\title{
The case for an emergentist approach
}

\author{
Bertus van Rooy \\ North-West University, Vanderbijlpark, South Africa \\ E-mail: bertus.vanrooy@nwu.ac.za
}

\section{Haidee Kruger}

Macquarie University, Sydney, Australia | North-West University, Vanderbijlpark, South Africa E-mail: haidee.kruger@mq.edu.au

\begin{abstract}
This paper sets out an argument in favour of emergentism as an alternative theoretical paradigm to nativism, arguing that it offers a coherent, evidence-based account of language structure, language acquisition, language evolution, and language change. A number of key tenets of the nativist approach are summarised first, including the nature of the presumed complexity of language, the poverty of the input argument against the learnability of language, the assumption of parsimony, the view of language as an innate, biological faculty, and the view of the primary function of language as cognitive representation rather than communication. This is followed by a presentation of the emergentist alternative, which hinges on the notion of the grammatical construction as the central unit in the emergentist approach. The properties of constructions, and how they can come into being with recourse to only domain-general cognitive processes, are presented, before the implications of this view for the structure, acquisition, evolution and change of language are discussed. Additional points of difference with the nativist position are highlighted, including the assumptions of non-parsimonious storage and the centrality of communicative interaction in the ontogenetic and phylogenetic development of language. Throughout the presentation, arguments are illustrated with reference to aspects of complementation in Germanic languages. The article concludes with a detailed case study of the wh-extraction construction, drawing on an analysis of corpus data from Afrikaans, to demonstrate how the construction-based, emergentist approach leads to an insightful analysis of a well-known construction, without having to make extensive assumptions about the underlying linguistic complexity and the need for innate mechanisms to enable the acquisition of such a complex construction.
\end{abstract}

Keywords: emergentism, nativism, construction grammar, Afrikaans syntax, wh-extraction 


\section{Introduction}

The linguistic paradigms that offer alternatives to nativism do not form a single theory and are designated by a number of different labels. However, there is a fair degree of correspondence among the various alternatives, and therefore much of what can be said about one approach is true of the others. This article offers emergentism as an alternative concept of linguistic structure and its development, which enables fruitful and insightful research in the (micro-)linguistic features of languages. ${ }^{1}$ The concept of emergentism adopted in this article extends beyond just the Emergent Grammar approach of Hopper (1998), and also includes the work of Bybee (2006, 2010), and Construction Grammar approaches (e.g. Croft 2001; Goldberg 1995).

Nativism, especially as represented by the generative approach, is characterised by a number of key postulates. A distinction is drawn between the use of language, and the ability to use language, framed as performance versus competence, where the latter is the object of enquiry (Chomsky 1965: 4). Furthermore, the structure of language is regarded as very complex, and hence the grammar of a natural language is assumed to be too difficult for a child to acquire through exposure to language data alone (Chomsky 1959: 43-44, 1986: 51-56). Chomsky (1986) formulates this as "Plato's problem", in terms of which the child can only acquire the grammar of the language if $s /$ he is assumed to have an innate language acquisition device that guides the process of language acquisition. Therefore, Chomsky (1965: 51, 1986: 2) aligns the generative approach with the tradition of rationalism, whereby a significant part of linguistic explanation is directed at determining the properties of the innate endowment of the child that enables the acquisition of the grammar of a language.

Emergentism adopts an inductive stance towards the process of language learning and grammar construction, in which the exposure to actual language use in interactive contexts plays a central role. Thus, performance data are all there is to the emergentist, who does not recognise competence as a separate object of enquiry. The emergentist approach views the language learner differently to the nativist. General cognitive abilities that enable learning across various cognitive domains are also regarded as adequate for the task of language learning, given authentic language-use data (Bybee 2010). The learner infers the grammatical structure gradually from repeated encounters with language (Bybee 2006; Sampson 2005), although at the earliest stages, emergentism does not attribute very abstract and generalised representations of the grammar of the language to the learner. Rather, representations are lowlevel, lexically rich constructions that only gradually become more abstract and schematic, as the language user is exposed to more examples and grasps more relationships among lowerlevel schemas (Bybee 2006, 2010; Lieven, Behrens, Spears and Tomasello 2003). Grammatical categories are not held to exist in advance as a priori categories in language-use data, but are constructed by the language user to the extent that they become useful in

\footnotetext{
${ }^{1}$ Alternatives to nativism are sometimes designated by the label "empiricism" (Chomsky 1965: 47; Sampson 2005: 6), suggesting a correspondence to the philosophical tradition of Empiricism, which is contrasted with the rationalist philosophical roots of nativism. In its narrower philosophical sense, it is a perfectly apt description of some of the points of departure, but it does not capture the implied description of grammatical structure of the term "emergentism", which we foreground in this paper. Emergentism not only rejects the rationalist assumption of innate ideas that guide human understanding, but also proposes that grammatical categories do not exist prior to the use of language. Rather, they come into being, or emerge, through repeated exposure to and use of language (Bybee 2006). The term "usage-based" also has wide currency, and while we are aligned with the tradition, the term itself is also less specific about the nature of categories.
} 
extracting schemas, or generalisations, from the data (Croft 2001; Hopper 1998). At the same time, emergentism takes the processing constraints imposed by the general architecture of the human brain very seriously, and sees a reciprocal relationship between language and the brain, such that language also assumes the shape it does because that is the form in which the brain is able to process it (O'Grady, Lee and Kwak 2009; O'Grady 2015), as represented by the Performance-Grammar correspondence thesis of Hawkins $(2004,2014)$, for instance.

Bybee (2010: 6) identifies one of the key questions in the debate between nativism and emergentism: "are the processes that give us linguistic structure specific to language or are they processes that also apply to other cognitive domains?" She proceeds by proposing a general guideline that should guide the investigation:

The best strategy for answering this question is to start with domain-general processes and see how much of linguistic structure can be explained without postulating processes specific to language. If this quest is even partially successful, we will have narrowed down the possible processes that have to be specific to language (Bybee 2010: 6-7).

She cautions that " $[t]$ he opposite strategy of assuming processes specific to language will not lead to the discovery of how domain-general processes contribute to linguistic structure" (Bybee 2010: 7). Nativists disagree with this strategy because of how they view the learning task awaiting the child and their assumption about the intrinsic complexity of linguistic structure. The task of mastering a grammar is held to be impossible through input data alone - it only becomes possible if an innate biological mechanism specific to language acquisition is postulated, consisting of principles that are specific to human language (Chomsky 1986; Pinker 1994).

The argument in favour of an emergentist approach presented in this article is structured as follows. A number of key tenets of the nativist approach are summarised first, including the nature of the presumed complexity of language, the poverty of the input argument against the learnability of language, the assumption of parsimony, the view of language as an innate, biological faculty, and the view of the primary function of language as cognitive representation rather than communication. This is followed by a presentation of the emergentist alternative, which starts off with the introduction of the grammatical construction as central unit in the emergentist approach. The properties of constructions, and how they can come into being with recourse to only domain-general cognitive processes, are presented before the implications of this view for the acquisition and evolution of language are discussed. Throughout the presentation, arguments are illustrated with reference to aspects of complementation in the Germanic languages. The article concludes with a more detailed case study of the wh-extraction construction, drawing on an analysis of corpus data from Afrikaans, to demonstrate how the emergentist approach leads to an insightful analysis of a well-known construction, without having to make extensive assumptions about the underlying linguistic complexity and the need for innate mechanisms to enable the acquisition of such a complex construction.

\section{The nativist position}

While nativist views are important to various linguistic approaches, in this article the focus will largely be on the generative paradigm and its incarnations since the 1950s. A cornerstone of 
generativism is the assumption that the structure of language is very complex (Pinker 1994: 124-125), and furthermore that the language data to which a child is exposed are not rich enough to account for the representations that are attributed to the mind of the child (Chomsky 1986: 7-8; Pinker 1994: 22, 31). This complexity is related to two properties in particular: that language is structure dependent (Pinker 1994: 40-41), and that it displays the property of recursivity, which enables the embedding of constituents to form structures of potentially infinite complexity and length (Pinker 1999: 9-11; Hauser, Chomsky and Fitch 2002).

Structure-dependency means that operations on language structure do not target words directly in terms of their linear order, but rather target the categories to which words belong, forming an invisible hierarchy of structures, usually called phrases. This view can be traced back to Chomsky's (1957) earliest argument against a finite-state model of grammar. A classical illustration of this property comes from wh-extraction, where an interrogative pronoun or adverb that is deeply embedded in a tree structure is extracted and ends up at the beginning of a syntactic sentence, but outside the clause from which it originates, as exemplified in example (1) (from Verhagen 2005: 119, after Chomsky 1977: 83, 118).

(1a) $\mathrm{Who}_{\mathrm{i}}$ did Mary say [that John kissed $\mathrm{t}_{\mathrm{i}}$ ].

(1b) $\mathrm{Who}_{\mathrm{i}}$ did Mary hope [that Tom would tell Bill [that he should visit $\mathrm{t}_{\mathrm{i}}$ ]].

Therefore, movement is only permitted because of a range of constraints defined on structures, rather than the linear order of words, such as the availability of an appropriate landing site for the wh-phrase in the specifier of the Complementiser Phrase (CP). The problem becomes more complex, and the importance of structure dependency therefore increases, as the complexity of the movement rule increases, illustrated by example (2), taken from Chomsky (1986: 153), where considerations of structure, as captured by terms like "islands", "subjacency" and "bounding", among others, constrain the possible landing sites of the moved constituents.

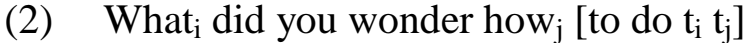

Example (2) illustrates that the two interrogative expressions, which originate in the final two positions, are moved to two separate landing sites, the specifier of the highest-level CP (what) and the complement of the verb wonder, which itself has to be a $\mathrm{CP}$ with another specifier landing site for the second interrogative element (how). Example (2) also illustrates longdistance dependency, which is a further factor that increases the complexity of language (Pinker 1994: 96-97).

Recursivity is the property that allows a structure belonging to a particular category to be embedded into a higher structure of the same kind, which allows a language to use a finite set of rules to generate an infinite number of actual sentences (Chomsky 1957; Hauser et al. 2002; Pinker 1994: 94-96, 100-101; Pinker 1999: 9-11). Pinker (1994: 86) notes that recursivity is at the root of the vastness and potentially infinite character of linguistic expressions. He illustrates the effects of complexity by referring to a claim in the Guinness Book of World Records that a 1300 -word sentence in William Faulkner's novel Absalom, Absalom! was once regarded as the longest sentence in English, which can be lengthened by embedding this very long sentence in higher clauses (as in example (3)), potentially infinitely. 
(3) [s Who cares [s that Pinker wrote [s that Faulkner wrote, [s "They both bore it as though in deliberate flagellant exaltation..."?]]]] (Pinker 1994: 87, clause boundaries added)

On the basis of properties such as structure dependency and recursivity, nativists like Chomsky $(1965,1986,2000)$ and Pinker (1994) are lead to postulate that language is not learnable from exposure to input data alone, but that acquisition has to be guided by innate principles of a specific kind. This has become known as the "poverty of the input argument" or "Plato's problem". The argument about the poverty of the input is supported by a number of further arguments (e.g. Chomsky 1972; Cook and Newson 1996: 93-105). One central supporting argument for the view is that children are able to produce forms they have not heard before, which is explained as the application of a rule that is more general than what is warranted by the input. Psycholinguists working in the nativist paradigm view these findings as providing support for an innate, specialised language acquisition mechanism (see, for example, Crain 1991; Crain and Pietroski 2002). Additionally, nativists claim that the input contains ungrammatical features and that patterns of interaction with caretakers make a negligible contribution to the process of acquisition as long as the input is comprehensible (Pinker 1994: 280-283; Pinker 1999: 215-216).

The proposed solution to Plato's problem is an innate endowment that contains a number of principles specific to language, which guide the process of language acquisition by limiting the number of possible hypotheses that can account for the data (Pinker 1994). In the principles and parameters version of generativism, for instance, a number of linguistic categories - Noun, Verb, Adjective, Preposition - and functional categories - Inflection and Complementiser - are assumed to be prewired in the brain. Alongside these are principles about their interaction, such as the X-bar structure of all phrases and a set of principles and parameters that constrain the possible structures and syntactic movement in all human languages (Chomsky 1981, 1986). In the more recent minimalist version (e.g. Chomsky 1995, 2000), there are still a number of operations - Merge and Move - that are also held to be prewired, although a large group of nativist researchers continue arguing for a richer innate endowment (e.g. Pinker and Jackendoff 2005). The task of the child is then to deductively parse the input data into the pre-existing categories, and set the values for parameters (Chomsky 2000: 61; Pinker 1994: 112).

A further reason postulated for the assumption of categories and principles of a very general nature is that the brain aims to economise the process of language learning and production. It aims for the maximally general statement of regularities, or "significant generalizations" (Chomsky 1965: 42), which is simultaneously applied in two domains. The evaluation of a theory of grammar aims for such maximal generalisations, with the grammar using the smallest number of symbols capturing the widest possible range of facts valued more highly (Chomsky 1965: 42-43). Furthermore, the grammar with the widest generalisations is regarded as the one that language-learning children will acquire (Chomsky 1965: 43). The overall X-bar theory is an instantiation of this principle, but germane to the empirical data analysed in this article is the structural equivalence that this view postulates between direct objects of transitive verbs and complement clauses (see Thompson 2002 for a critique of the categoryhood of various kinds of "complement clauses"). If maximal generalisation is the 
aim, then the noun phrase in (4a), infinitive clause in (4b) and finite clause in (4c) will all be regarded as direct object (complement) of the verb aangesê 'told'.

(4a) Die Cheetahs het die Natal Sharks twee weke gelede [овJ die stryd] in Bloemfontein aangesê. (TK, adjusted)

'The Cheetahs joined [овл battle] with the Natal Sharks two weeks ago.'

(4b) Die bestuurder het sy bemanning aangesê [овJ om uit die voertuig te klim]. (TK)

'The driver told his crew [овs to get out of the vehicle].'

(4c) Ek is aangesê [овј dat ek dalk my werk kan verloor omdat ek in die parlement gepraat het]. (TK)

'I was told [овл that I could perhaps lose my job because I spoke in parliament].'

The idea of a parsimonious apparatus for grammatical description takes a further step in the principles and parameters approach with the elimination of "grammatical constructions" (Chomsky 1981: 121-122, 1986: 70-80). Rather than admitting the existence of patterns that are specific to individual languages, as the transformation rules of the earlier versions of Chomsky's grammar $(1957,1965)$ still recognised, from the 1980s, the attempt was to eliminate language-specific rules in favour of very general principles that constrain movement, leaving only a few triggers (such as passive morphology) as the reason why movement takes place at all. If a rich set of innate principles is postulated, at a level of abstraction much higher than individual languages, then an account can be formulated for variation across languages in combination with parameters that have to be set. By contrast, the language-specific quality of individual constructions is a problem insofar as these cannot be attributed to a genetic endowment shared by all children, irrespective of the languages they acquire. In the extreme, this has led to the position of the Minimalist Programme (Chomsky 1995), where many of the familiar principles and parameters, and the design principles of grammar developed during the 1970s and 1980s were abandoned. This, in turn, led to the point where Hauser et al. (2002) proposed that recursivity is the only true innate universal of language.

Regardless of the precise mechanisms, within the nativist framework language is viewed as an innate, specialised biological faculty, hardwired into the human brain. Therefore, questions about the origins of this faculty are framed as questions of how the human brain evolved this specialised faculty: the "evolution of language users" (Christiansen and Chater 2008: 497) to enable language. A number of answers have been proposed to this, which Christiansen and Chater (2008: 489) group into two main views. The first view is that the specialised brain mechanisms enabling language evolved gradually through adaptation, becoming genetically entrenched in homo sapiens (Pinker and Bloom 1990; Pinker and Jackendoff 2005). The second view is that the genetic endowment of language did not emerge through gradual adaptation, but through non-gradualist means, among which a number of mechanisms have been proposed (see Christiansen and Chater 2008 for an overview of some of these; Chomsky 2007 for his position that language emerged suddenly from a single individual mutation). Both these views assume that the explanandum of language evolution is the development of "brain mechanisms specialized for language" (Christiansen and Chater 2008: 489).

\footnotetext{
${ }^{2}$ Unless otherwise specified, all Afrikaans examples in this paper are taken from the Taalkommissiekorpus, a 57million-word corpus of contemporary written Afrikaans, for which we use the abbreviation "TK". Where an example is simplified through the omission of, for instance, adverbial clauses, it is indicated as "TK, adjusted".
} 
A last point on which there is broad consensus in the nativist paradigm is that since language is an innate, biological faculty, the development of language, both ontogenetically and phylogenetically, does not depend in any significant way on communicative interaction. Chomsky (2007: 22) argues that language functions, and evolved, primarily as an instrument of thought - not communication. Berwick, Friederici, Chomsky and Bolhuis (2013: 90-91) posit that the computational mechanism for language minimally involves "some operation that constructs new representational elements $\mathrm{Z}$ from already-constructed elements $\mathrm{X}, \mathrm{Y}$ ”, an operation called "Merge", which is at the core of language. Merge operates on structural mental linguistic representations, and not on the sequential order of words. The dimension of structural mental linguistic representations is called "internalisation". In contrast, linear order is associated with "externalisation": whenever humans produce or perceive language, physical constraints of the sensory-motor system demand linearity. Externalisation, in this sense, is "the mapping from the internal linguistic representations to their ordered output versions" (Berwick et al. 2013: 91). The upshot of this view is that communication is regarded as a component of externalisation, viewed as an "ancillary" function of language and not its primary function. The primary function of language, and the object of investigation, is the internalisation process, where language "serves primarily as an internal "instrument of thought"" (Berwick et al. 2013: 91). Given this emphasis, it is not surprising that the nativist paradigm discounts that social and interactive forces exert selection pressures in the evolution of language.

A number of theoretical and empirical challenges have been raised to the nativist position set out in this section. It has been questioned whether language is as complex as is assumed by generativists, and whether the cognitive representation of language is as hierarchical as proposed by the generativist model (Verhagen 2005; Sinclair and Mauranen 2006). To the extent that language indeed displays features of hierarchical organisation, these need not be regarded as innate, but can be explained as the consequence of chunking (Bybee 2010) and an efficient solution to work around memory restrictions (Sampson 2005). Scholars have demonstrated empirically that the input children receive is not as impoverished as supposed and that children's language output corresponds closely with features of the input (Diessel and Tomasello 2001; Lieven et al. 2003; Sampson 2005). Others have demonstrated that much of language acquisition and development can be accounted for by general cognitive processes (Bybee 2010). The corresponding evolutionary corollary is that the evolution of language does not require the concomitant evolution of a specialised brain mechanism for language, but that language, instead, has evolved to suit human brains (Hawkins 2004, 2014; O’Grady 2012), or as Christiansen and Chater (2008: 490) posit:

We propose that language has adapted through gradual processes of cultural evolution to be easy to learn to produce and understand. Thus, the structure of human language must inevitably be shaped around human learning and processing biases derived from the structure of our thought processes, perceptual-motor factors, cognitive limitations, and pragmatic constrains. Language is easy for us to learn and use, not because our brains embody knowledge of language, but because language has adapted to our brains.

Furthermore, scholars like Givón (2005) and Tomasello (2008, 2014) have proposed that communicative interaction is an essential element of language genesis and acquisition, which challenges the view of language acquisition and evolution in the nativist tradition. Implicit in 
the larger role for communicative interaction is a rejection of the competence/performance distinction that has characterised generative thinking.

In the following section, we consolidate these challenges to the nativist position, arguing in favour of an emergentist alternative. All of this is presented within the context of construction grammar, in which the grammatical construction rather than abstract (presumedly innate) principles is the central element of linguistic representation.

\section{The emergentist position}

For the emergentist, the construction is the central unit of analysis, which stands in sharp contrast to Chomsky's $(1981,1986)$ rejection of constructions as taxonomic artefacts, as discussed above. A construction is a pairing of a linguistic form with a meaning or function, such that some element of the meaning of the form is not strictly predictable from its constituent parts (Goldberg 1995: 4), and the overall meaning in context represents the fusion of the meanings of particular words with the construction meaning (Goldberg 1995: 140). Taylor (1995: 206) argues that the meaning of a construction is an "experientially primitive gestalt" that is "cognitively simpler than any of its component parts". A construction-based view of grammar, like cognitive (Langacker 1987: 3, 12) and functional (Croft 1995) linguistics more generally, sees no strict differentiation between semantics and syntax, as the generativist view does, but rather embraces the relationship between linguistic form and meaning as central to an explanation for the shape that language takes.

Constructions range from very general and abstract to instances that are so specific that they are regarded as fixed idiomatic expressions by language users. On the more general side of the spectrum, construction grammar recognises very general categories, such as the transitive construction, which typically has the form set out in example (5).

$\begin{array}{llll}\text { (5) Form: } & \text { NP1 } & - \text { VERB } & - \text { NP2 } \\ \text { Meaning: } & \text { Agent } & - \text { Process } & - \text { Patient }\end{array}$

In emergentist or cognitive approaches, the transitive construction is specified further in terms of properties, such as that the subject/agent is an animate being acting with volition and the object/patient is a concrete, inanimate thing either affected or created by the action of the verb (Taylor 1995: 206-207). Many of the properties attributed to the subcategorisation frame in generative approaches are transferred to various argument constructions, starting with the transitive construction, but extending to a number of more specific constructions, discussed in detail by Goldberg (1995). However, while the categories of the transitive construction are very general, neither all verbs nor all combinations with noun phrases are allowed. Taylor (1995: 218-220) points to a number of transitive constructions in English that are not possible in German, and hence argues that the constraints against extension of the prototypical transitive construction are stronger in German. For example, when the patient (NP2) is not independent of the agent, but part of the body, German requires a reflexive construction, as illustrated by (6).

(6) Erhat sich die Zähne geputzt. he has himself.DAT the teeth.ACC brushed 'He brushed his teeth.' 
Taylor (1995: 219) also notes the constraint against the use of the transitive construction when "the patient does not undergo a change of state as a result of the action of the agent", in which case the verb may be reflexive and the patient be realised in another case than the accusative, for instance the genitive, as in example (7).

(7) Ich erinnere mich seines Namens.

I remember myself.ACC his.GEN name.GEN

'I remember his name.'

A construction may combine schematic/general elements alongside more specific ones, for instance the construction in (8a), which is instantiated by the specific examples in (8b) and (8c) (Bybee 2010: 28, after Fillmore and Kay 1999).

(8a) Form: WHAT IS X DOING Y?

Meaning: surprise at incongruity with a hint of disapproval

The elements $\mathrm{X}$ and $\mathrm{Y}$ in the construction are schematic, and may be occupied by a number of instantiations, although $\mathrm{X}$ is typically a noun phrase and $\mathrm{Y}$ a prepositional phrase. However, the rest of the construction is formulaic, with the interrogative formula WHAT IS ... DOING fixed, and not subject to variation. While the expression can be analysed as a specific interrogative (or wh-question), there is an unpredictable element to the meaning of the instantiations of the construction that goes beyond the meaning of an interrogative, namely the pragmatic sense of surprise and disapproval. In instantiation (8b), the diner wishes to convey disapproval at the presence of the fly in the soup, whereas in instantiation (8c), the speaker is surprised and even shocked at the fact that the addressee holds a knife in his/her hand. These are not mere pragmatic inferences from context, but form part of the meaning of the construction whenever it is used, and are therefore attributed to the construction itself.

(8b) Diner: Waiter, what's this fly doing in my soup?

Waiter: Why, madam, I believe that's the backstroke.

(8c) What are you doing with that knife?

One of the most fundamental ways in which an emergentist approach differs from nativist accounts is its rejection of the assumption that linguistic categories are aprioristic. By aprioristic, we mean that the design of language, or at least some of its critical properties, needs to be given in advance. By contrast, an emergentist argues that the generalisations that lead to the formation of categories emerge from experience with language. The properties of grammatical constructions come to the fore here. Constructions are to be regarded as inductive generalisations over instances of real language use encountered by a speaker (Goldberg 1995: 133). These are not given in advance as skeletons into which data are parsed. It is in the nature of inductive generalisation from actual examples that fully productive and general constructions are likely to be the exception and not the norm. Most constructions occupy a space between the extreme ends of the continuum that range from fixed idiomatic expression to highly abstract general and exception-free schemas (Croft 2007; Goldberg 1995: 136-138).

To make the case for an emergentist approach, it is necessary to explain how constructions arise with recourse to general cognitive mechanisms only, without having to rely on pre- 
existing categories or processes that are assumed to be innate and specific to language (O'Grady 2008: 488-451). Bybee (2006: 714) argues that grammatical structure emerges from repeated exposure to usage events from which inductive generalisations are drawn by the language user. Repetition, which in essence requires memory, and categorisation, the ability to recognise a pattern, are the two key general cognitive abilities that enter into category formation of this kind (Bybee 2010: 7; Langacker 1987: 99-146).

Bybee (2010) posits that five such domain-general cognitive processes, shown to be fundamental to human cognitive processing, can account for much of the development of grammatical structure: categorisation, chunking, rich memory storage, analogy, and crossmodal association. Categorisation, as already pointed out, is the most pervasive, and interacts with all the other processes. Categorisation is the process by means of which the linguistic exemplars encountered in exposure to language are "recognized and matched to stored representations" (Bybee 2010: 7). ${ }^{3}$ Chunking allows for sequences of units to be combined in more complex units, and is basic to the formation of sequential units, which are eventually stored and accessed as a single unit. Chunking and categorisation combined are the powerful mechanism by which conventional sequences, or constructions, of varying degrees of analysability, schematicity and productivity develop (Bybee, 2010: 7). Analogy is the crucial cognitive process that allows novel utterances to be produced by extending an existing construction. Accordingly, categorisation is necessary: the component parts of an existing construction representation must be identified as category slots that may be "filled" by alternative items that are similar to existing items (Bybee 2010: 8). Rich memory storage assumes that language representation is founded on the rich representation of exemplars (actual tokens of encounters with language), stored with details of the encounter with language: phonetic and morphosyntactic detail, semantics, context of use, and pragmatics - even including redundant information (Bybee 2010: 7, 12). This stands in stark contrast to the parsimonious storage invoked by generativist approaches. From these representations, through categorisation, representations are developed and extended. Lastly, these representations involve cross-modal associations, whereby certain forms become associated with certain meanings - which may include inferential or pragmatic meanings and semantic meanings. The principle involves assigning meaning to the largest possible chunk (rather than decomposed to constituent parts) (Bybee 2010: 8). These processes, applied in an iterative fashion, create categories of units, and sequential structures such as constructions and constituents, demonstrating varying degrees of analysability, schematicity and productivity, as Bybee (2010) demonstrates.

O'Grady et al. (2009: 70-74) distinguish between two strands within emergentism, an inputbased and a processor-based approach, although these two approaches are compatible. They situate construction grammar (e.g. Goldberg 1995) within the input-based strand, in which frequency factors play a significant role, but note that proponents of this strand acknowledge the importance of processability considerations, while conversely, the processor-based strand also acknowledges the importance of input factors. While we acknowledge the value of the

\footnotetext{
${ }^{3}$ There is a competing tradition of thought among cognitive linguists that prototypes and schemas are more abstract mental representations of the shared attributes of the prototypical instances, rather than the cluster of stored examples approach taken by Bybee (2010). See Langacker (1987: 16-17) and Taylor (1995: 59-68) for the alternative view. For the purposes of our discussion, the degree of abstractness and generality of mental representations is not critical, since the two approaches share the view that categories are built up inductively and incrementally, rather than by matching linguistic experience to aprioristic categories.
} 
processor-based emergentist approach, considerations of space make it impossible to do full justice to that approach within the present scope.

Emergentism holds that constructions and the categories that contain them emerge from experience with language, processed by domain-general cognitive processes, and that they are not given in advance. In this sense, emergentism adopts a more radical viewpoint than some of the other strands in cognitive linguistics, represented by Langacker (1987: 12-13) for instance, which do not make a commitment for or against the domain-specificity of the cognitive infrastructure that supports the acquisition and use of language. Learning a language, in the emergentist view, does not need predefined design, but only general cognitive abilities such as categorisation, chunking and analogy. An argument for an emergentist approach will be supported if data can be found to show how linguistic constructions develop inductively during language acquisition, without requiring reference to pre-existing categories. The overview of research on the role of analogy in child language in Bybee (2010: 64-66) demonstrates that the domain-general cognitive process of analogisation offers an alternative explanation for children's ability to produce novel utterances: children store their experiences with language as exemplars, accruing representations. These are gradually expanded by analogisation and categorisation to arrive at more general patterns that become increasingly abstract.

Strong evidence for this view of language acquisition comes from many usage-based studies of child language acquisition (see Tomasello 2003 for an overview). Lieven et al. (2003), for example, investigate the degree to which novel utterances in early child language are related to previous utterances. They find that the majority of novel utterances are limited modifications of previous utterances, and that this productivity can be accounted for by the use of schematic constructions that are modified in incremental ways. These constructions are often lexically specific, but become more complex over time (Lieven et al. 2003: 365). Goldberg (1995: 40-43) reviews a range of child language acquisition studies on the development of different argument structure constructions. She notes that a small number of lexical verbs, in English for example do, go, make and put, are used from early on, in ways that the more general argument constructions are used. These constructions correspond closely with basic human perceptions of event types, and are thus motivated independently from language in general cognition. Over time, these basic constructions are extended, incrementally, to new verbs with more specific meanings, and to constructions that go beyond basic event construals to more sophisticated forms of information representation, such as interrogatives or cleft constructions.

Complement clauses, as in example (4b) and (4c) in section 2, are a prime example of recursion and syntactic complexity in many generative analyses. If the acquisition and development of these clauses can be explained without recourse to aprioristic, genetically transmitted categories and processes, the case for emergentism will receive further support. Diessel and Tomasello (2001) investigate the acquisition of finite complement clauses in English-speaking children aged $1 ; 2$ to 5;2. They conclude that the origin of finite complementation is not as a complex construction that contains two clauses of which one is embedded in the other. They show that the acquisition of finite complement constructions in English proceeds from the formulaic (monoclausal, with no conceptual or syntactic embedding), to the performative (biclausal, with syntactic but no conceptual embedding), to the assertive (biclausal, with syntactic and conceptual embedding) functions. These variants 
are illustrated by the examples in (9). ${ }^{4}$ Example (9a) illustrates the monoclausal earliest precursor to complement clause constructions, in which the two clauses are loosely coordinated and can freely invert their order. The CTP I guess is fully formulaic, does not allow variation, and functions like an adverbial rather than a main clause into which the complement clause is embedded. In (9b), the performative use is illustrated, where the CTP I believe is not presented as an assertion of the speaker's belief, but as an epistemic hedge of the complement clause. While there is syntactic embedding, there is no conceptual embedding. The performative use is more productive in that a larger array of verbs can be used with a bigger range of subjects. Only in example (9c) can we observe the assertive function, in which the CTP functions as a conventional main clause that determines the profile of the overall expression (Langacker 1991: 440).

(9a) [You're right], I guess OR I guess [you're right].

(9b) I believe [that this is a mistake]. $=$ this is probably a mistake

(9c) Peter remembered clearly [that he had seen this guy before]. = Peter actually remembered

However, there is considerable variation among individual verbs - with some verbs remaining largely restricted to the formulaic use, and others showing a clearer developmental pattern. Also, there is a group of verbs (including say, tell, pretend and show) that are used in complement constructions later on than others, and do not typically occur in formulaic uses but are used performatively or assertively from the outset (Diessel and Tomasello 2001: 133). Diessel and Tomasello (2001: 133) interpret their findings as evidence for the development of a construction network that becomes increasingly schematic:

... children's early use of sentences including say, tell, pretend, and show is item-specific; the sentences are organized around individual verbs and not yet licensed by a general CTV/COMP-clause schema (or rule). Such a schema emerges only later through generalization across a large number of itemspecific CTV/COMP-clauses. In general, what children eventually learn is a network of interrelated constructions.

Studies such as these also raise an important challenge for the poverty of the stimulus argument. A number of scholars have provided empirical evidence that the assumption that linguistic input is "impoverished" in comparison to presumed cognitive representations is a fallacy (see MacWhinney 2010; Sampson 2002, 2005; Pullum and Scholz 2002). More fundamentally, as Tomasello (2009: 84) points out, if one views grammar as a structured inventory of constructions, rather than as an algebraic set of rules, the problem of the poverty of the stimulus disappears:

The problem is that the argument is formulated in terms of a formal generative grammar as adult endpoint and a child who has available only behaviouristic learning theory - which enables him or her only to string words together in a Markov chain (with no understanding of phrasal organization or any other structure-function correlations), making blind

\footnotetext{
${ }^{4}$ In example (9), the conventional matrix clause (which we prefer to call the "complement-taking predicate", abbreviated to CTP, following Thompson 2002) is underlined, and the complement clause is enclosed by brackets.
} 
associations and inductive inferences in the process (with no conceptual understanding of linguistic function at all). But, as Tomasello (2003) argues, there is no poverty of the stimulus if linguistic competence is conceived not as a set of formal, algebraic rules but rather as a structured inventory of meaningful grammatical constructions, with the child possessing sophisticated learning skills involving categorization, analogy and distributional learning. There is certainly no poverty of the stimulus when it comes to the particular constructions children learn.

The emergentist view of child language acquisition as the gradual development of an increasingly more schematic and abstract network of constructions, based on actual experience with language mediated by domain-general cognitive processes, is echoed by the gradualist view of the evolution of language. Crucially, the emergentist view of language evolution views evolutionary processes as operating on language itself, rather than on the brain mechanisms that produce language. Christiansen and Chater (2008) present a number of arguments against the nativist assumption that the language faculty, as biological endowment or specialised brain mechanism, either came about through adaptation, or through alternative routes. Instead, they propose that it is language itself that "has adapted through gradual processes of cultural evolution" (Christiansen and Chater 2008: 490). In this view, gradualism and variability are critical features. In biology, a very complex organ, such as the human eye, develops very slowly over a long period of time in small increments. Initially, very moderate sensitivity to light confers an adaptive advantage to the organism that possesses such an ability, and over time, variations in light sensitivity arise and organisms with the advantage outbreed the other members of the species, until something like eyesight develops. The converse is also true: among fish who live below a certain depth, where no light passes through, there is no selective advantage to eyesight and such fish tend to be blind, unlike their ancestors who lived at higher depths (Dawkins 2009: 351-355).

If this line of reasoning is transferred to cultural objects such as language, a similar logic applies, although the process of selection is somewhat different. As Christiansen and Chater (2008: 499) point out, viewing language itself as an evolutionary system has important implications for the unit of selection in language evolution. In the constructionbased, emergentist view, the basic units of selection are individual constructions. The factors that condition the selection of a construction include its individual properties (such as frequency), as well as its relationships to other constructions in the system, in terms of syntactic, semantic or pragmatic relationships (Christiansen and Chater 2008: 499). Aspects of the social ecology of language use also play a crucial role, such as the convergence between speakers who form a speech community and, therefore, choose forms to maximise agreement between their speech patterns (Croft 2000: 32). The important role of frequency in the development of linguistic structure is well researched (see, for example, Bybee 2006), and groups of related constructions are associated to form the basis of increasingly abstract generalisations. This is the foundation of grammar, which is not an abstract system of formal rules hard-wired in the brain, but rather "a distributed system of local generalizations across partially overlapping constructions" (Christiansen and Chater 2008: 499) that develops from experience with language, by means of the application of general cognitive processes.

The way in which languages change by means of the development of new constructions is also accounted for by this model. An existing structure of language is extended to a new function 
without changing its form, and therefore becomes functionally polysemous. This view extends the idea of exaptation from the biological to the cultural domain (Dennett 2013: 257). The polysemous structure is entrenched in a particular function, and over time, grammaticalisation (Hopper and Traugott 1993) takes place, so that the various constituent elements attain the status of a unit, and are subject to processes of erosion, giving rise to a formal split that correlates with the original functional differentiation (see Givón 2009). A useful example of this can be found in the development of complement constructions in the Germanic languages, which is, as previously noted, a prime example of syntactic complexity that putatively necessitates the assumption of a rich, genetic endowment as precondition for the acquisition of language. Givón (2009) argues that all embedded clauses have their origin in independent (paratactically linked) clauses that have undergone grammaticalisation of one of the two predicates of the precursor clauses (Givón 2009: 62). Complement clauses, specifically, have their origin in two adjacent independent clauses, where the first clause is the origin of the complement-taking clause, and the second clause the origin of the complement clause, which is then incorporated to various degrees into the complement-taking clause. With reference to Heine and Kuteva (2007: 241-242), Givón (2009: 95-96) argues that the original paratactic precursor of the complement clause construction in the Germanic languages is as set out in examples (10a) and (10b):

(10a) I want it, to do it > I want to do it.

(10b) She knew that, he did it > She knew that he did it.

The embedded clause represents an event that "is treated analogically as a nominal object of the main clause" (Givón 2009: 73, emphasis original). Givón (2009: 73, 141) also notes that the CTP verbs are all transitive verbs with direct object noun phrases in their original usage, prior to the emergence of complement clauses. As part of the grammaticalisation of the complement clause construction, the embedded clause may lose some of the markers of its finiteness and take on overt markers of its subordinate status (Givón 2009: 74; Langacker 1991: 439-449).

A number of scholars have argued that a second round of grammaticalisation of some complement-taking predicates is currently taking place, whereby the complement construction is first functionally differentiated into a propositional and interpersonal function, which over time is associated with different structural features. The development of comment clauses, modal particles or epistemic parentheticals is generally interpreted as proceeding through grammaticalisation from complement-taking predicates (see Brinton 2008; Kaltenböck 2013; Thompson and Mulac 1991). Kruger and Van Rooy (2015) show that in Afrikaans, the functional differentiation between propositional and interpersonal meaning correlates significantly better than chance with the differentiation between two forms. Example (11) illustrates the propositional use, in which the CTP $e k$ glo 'I believe' is used to denote a claim about the speaker's belief, whereas the interpersonal use, in example (12), does not amount to a claim about the speaker's belief, but represents an epistemic hedge, which is further emphasised by the co-occurrence of another, adverbial, hedge seker 'probably'. Therefore, in example (11), the content of the CTP forms the object of conceptualisation and is discourse-central. The mental activity of the verb of the CTP is projected of its subject, and the complement clause is a projection attributed to the main-clause subject. In contrast, in example (12), the content of the complement clause is the discourse-central object of conceptualisation, and the CTP is a modifier to the complement clause, fulfilling the function of intersubjective coordination. The 
formal differentiation is that the complement clause in example (11) takes a complementiser dat 'that', followed by subordinate-clause word order, whereas no complementiser is used in (12) and the complement clause has main-clause word order.

(11) Ek weet wel van die suksesverhale van baie Christene wat ryklik geseën is nadat hulle getrou aan God hul tiende gegee het, en ek glo dat God se kinders nooit as gevolg van hul offers aan Hom gebrek sal ly nie. (TK) $^{5}$

'I do know of the success stories of many Christians who have been richly blessed after they faithfully gave their tithe to God, and I believe that God's children will never suffer any lack as consequence of their offerings to Him.'

(12) ... Isabel waag dit om te vra: "Het tante my al vergewe? Ek glo Eben het tante seker alles vertel." (TK)

'Isabel dares to ask, "Have you forgiven me yet, auntie? I believe Eben has probably told you everything."”

This grammaticalisation depends on a process in which the function of the CTP (like think or believe) is differentiated in a process of subjectification "whereby forms and constructions that at first express primarily concrete, lexical, and objective meanings come through repeated use in local syntactic contexts to serve increasingly abstract, pragmatic, interpersonal, and speaker-based functions" (Traugott 1995: 32). Boye and Harder (2007: 591) point to substantial cross-linguistic evidence for the movement from the propositional use (which they regard as lexical, objective and primary) to the interpersonal use (which they regard as grammatical, subjective and secondary) in the development of evidential grammatical markers. In some instances, the grammaticalisation process is complete, in that the grammaticalised form no longer has the same morphosyntactic form as the lexical form it is derived from. Traugott (1995) discusses a number of such subjectively grammaticalised constructions in English, including let us, be going to, rather than and a variety of stance adverbs. The forms maybe (English) and måske or kanske (Danish), which evolved from complement-taking constructions with a modal can or may and a main verb meaning happen or be (It may be that...) are additional examples (see Boye and Harder 2007). In Afrikaans, the adverbial use of glo 'apparently' is derived from the CTP verb glo 'believe' (see example (13a)), whereas gewis 'definitely' is derived from wis, the archaic irregular past tense form of the verb weet 'know' (see example (13b)).

(13a) Die aanbeveling van 'n ondersoekpaneel van die regering vroeër dat 'n moratorium op die verkoop van eiendom aan buitelanders geplaas word omdat dit glo pryse opjaag, het wêreldwyd opslae gemaak. (TK)

'The earlier recommendation of an investigation panel of the government that a moratorium should be imposed on the sale of property to foreigners because it apparently drives prices up made headlines across the world.'

(13b) Hy is 'n Rus van geboorte, maar Quint, verseker hy, is 'n Italiaanse van. Philippe? Gewis Frans, en dan borduur hy, as enigste kind, voort oor sy ma en pa. (TK)

'He is Russian by birth, but Quint, he reassures, is an Italian surname. Philippe? Certainly French, and then he elaborates, as only child, about his mother and father.'

\footnotetext{
5 The entire construction under discussion, CTP and complement clause, is printed in italics. The CTP is underlined, extending to the complementiser when present.
} 
A key tenet of evolution is that there is no prespecified design. Biological organisms do not evolve to achieve a certain shape; evolution is non-teleological. Tiny variations in the genes lead to minor selectional advantages that eventually become the norm for a species. Likewise in cultural evolution, it is not necessary to assume that a prespecified goal acts as an attractor for a structure (Dennett 2013: 275). A particular form gradually changes with use and eventually it becomes entrenched as a new construction. Christiansen and Chater (2008: 504-505) emphasise that language evolution through cultural transmission occurs incrementally, shaped by a variety of constraints that are generally below the surface of conscious awareness: "speakers do not deliberately contemplate syntactic reanalyses of existing structures, bleach the meaning of common verbs so that they play an increasingly syntactic role, or collapse discourse structures into syntax ..." (Christiansen and Chater 2008: 505). Rather, these changes occur in language because they confer certain processing or communicative advantages, leading to their increased use, and eventual entrenchment (Croft 2000: 31-32).

Therefore, the emergentist view, in contrast to the nativist, perceives the communicative function of language as primary in the ontogeny and phylogeny of language. Tomasello (2008: 9-11) sees two dimensions to this. Firstly, in this view "it is only within the context of collaborative activities in which participants share intentions and attention, coordinated by natural forms of gestural communication, that arbitrary linguistic conventions could have come into existence evolutionarily". For language to develop, in the first instance, shared attention, cooperation and communicative intent are necessary. In this cooperative context, human cognitive skills of learning, imitation and inference account for the development of language as a set of arbitrary conventions. However, as Tomasello (2008: 10) points out, a second evolutionary step is necessary. To explain the origins of human languages "... we also need cultural-historical processes in which particular linguistic forms are conventionalized in particular speech communities, and then sequences of these are grammaticalized into grammatical constructions, and then all of these conventions and constructions are passed along to new generations via cultural learning". Social interaction and communication are central to both these steps, and a basic precondition for the development of both language, and languages.

The emergentist alternative takes the construction as starting point of its analysis. Constructions are not maximally general, but arise as inductive generalisations over the actual (performance) data to which a language user is exposed. Constructions develop incrementally during language acquisition, without some prior design guiding their development. Such development is constrained by the usefulness of a construction during communication and by the possibilities and limitations of the human brains that have to process it. The development of constructions can take place under guidance of general cognitive mechanisms that are also relevant to other parts of human cognition, and need not be specialised for language or language acquisition, and hence no genetic endowment needs to be postulated to account for the grammars of human languages.

\section{Case study: a construction-based emergentist analysis of wh-extraction}

To demonstrate the insights attainable through an emergentist approach, in this section we examine the wh-extraction construction in Afrikaans in more detail (for emergentist alternatives to the analysis of other constructions, also see O'Grady 2008, 2015). Whextraction has enjoyed much attention in generative theorising over the years. It rose to 
prominence in the wake of Chomsky's (1977) paper devoted to wh-movement, formulated in the framework of the time, and served as a central piece of evidence for the $\mathrm{CP}$ and the differentiation between the head and specifier position of the CP. In standard textbooks over the years (e.g. Radford 1983, 1997; Cook and Newson 1996; Hornstein, Nunes and Grohmann 2005), the construction has attracted ongoing attention (e.g. Stroik 2009) and the "standard analysis" is constantly updated to fit changing theoretical positions. What remains constant is that, in some languages, an interrogative element originates in a complement clause that is embedded in one or more higher clauses, and then moves, cyclically, to its ultimate landing position in the specifier of the CP. Languages vary according to whether such movements take place at all, as opposed to leaving the wh-elements in situ, or if movement takes place whether all or only some wh-elements move (Stroik 2009: 55).

Verhagen (2005) offers a usage-based alternative account of the wh-movement construction in Dutch that challenges nativist assumptions about the complexity of the structure. He examines corpus evidence on wh-extraction, and concludes that it represents a construction with very specific lexical content and a very specific function, that is nowhere near as productive and general as the range of forms examined in generative analyses. The subject of the highest level clause is usually the second person (singular) pronoun, you in English or jij/je/u in Dutch, and the verb is usually think/denken. This leads Verhagen (2005: 124) to a prototype construction of WH-DENK-2 ${ }^{\text {ND }}$ PERSON-DAT-X for Dutch, from where it extends slightly to other elements, either a different subject or a different, semantically-related verb, but never both (Verhagen 2005: 126). In a grammaticality judgement task using invented sentences, deviations from the prototype are judged with increasing severity by native speakers of Dutch, where an example like (14) is judged ungrammatical (Verhagen 2005: 127-128):

(14) What did the trade union leader concede to a journalist after the press conference that the workers had done?

Verhagen (2005) used invented sentences for the simple reason that such extensive deviations from his construction prototype were unattested in the corpus data. The meaning of the construction, in his view, is to invite the addressee to engage in cognitive coordination with the speaker in respect of some content, which is expressed by the "embedded complement clause". Verhagen (2005: 126) draws an important conclusion from this analysis:

The result has dramatic consequences for the role of the phenomenon in syntactic theory. The properties of 'Wh-extraction' do not follow from general properties of complementation, and thus also should not be accounted for in such general terms. The template licensing such constructs constitutes a relatively concrete, low-level pattern, which has some properties that do not percolate upwards in the network to the level of productive rules. In other words, the fact that certain complementation sentences seem to contain displaced constituents is no evidence that such displacement follows from any general property of complementation; in this case, they instantiate a low-level template.

Verhagen's (2005) alternative account of wh-extraction provides counter-evidence to the analysis that assumes a rich array of structural descriptions, binding and movement principles, and embedded clauses. His point is that while very complex clauses can be constructed by a linguist using "introspection" as source of evidence, such examples conjured up by the 
armchair linguist do not occur in real language use, and moreover mislead the linguist to assume complex structures where there are none. It is interesting to note that even a minimalist theorist such as Stroik (2009: 56) concedes that scholars within his paradigm disagree about the grammaticality of a range of examples in English. This observation draws attention to a critical methodological difference between the nativist and emergentist paradigms: emergentists are committed to usage-based data, and increasingly look towards linguistic corpora as sources of primary data, while regarding invented examples and intuition as less reliable sources of evidence. However, Verhagen's (2005) data are quite limited, as he only managed to extract 43 examples of "long-distance wh-movement" from his corpus. In a pilot study of wh-extraction in English, Gast, Bickel and Bierlandt (2011) analyse a random sample of 400 wh-extraction clauses from the British National Corpus, and their findings for English correspond closely to those reported for Dutch by Verhagen (2005). However, the Gast et al. (2011) study is an unpublished conference presentation as far as we can ascertain, and does not report on issues such as sampling procedure and whether or not multiple whelements even occur in their data. They do not report on any such findings, but it appears as if Verhagen's (2005) criticism of generative analyses based on his small corpus sample from Dutch extends to English. Nevertheless, given restrictions on scope and methodology in both these studies, it seems prudent to undertake a more comprehensive analysis of wh-extraction. To test the generality of the claims, we examined wh-extraction in Afrikaans, using the Taalkommissiekorpus for more data. Du Plessis (1977) aligns the analysis of wh-extraction in Afrikaans with the overall thrust of generative scholarship at the time, but since then, there does not appear to have been any new research on this construction in Afrikaans.

The Taalkommissiekorpus (Taalkommissie van die Suid-Afrikaanse Akademie vir Wetenskap en Kuns 2011) contains 57 million words of written Afrikaans and is thus an adequate data source of the standard variety of the language. All the wh-words listed by Ponelis (1979: 380381) were extracted, using WordSmith Tools (Scott 2012), but limited to instances with a capital letter to restrict the initial search to sentence-initial position. A total of 73,609 instances were recovered, but the majority did not represent wh-extraction from embedded complement clauses. To identify the cases of wh-extraction, we examined the concordances of the 20 most frequent verbs that collocated with each of the wh-words, as well as all verbs that occurred at least 50 times (i.e. once per million words) to the right of the wh-words. All verbs that yielded any instance of a wh-extraction construction were checked for further instances with all other wh-forms too. In this way, we hope to have identified all or almost all of the relevant instances of the construction from the entire corpus.

A total of 881 examples were extracted in this way, giving a relative frequency of 15 instances per million words in the corpus, and one wh-extraction construction per 100 sentence-initial wh-words. An important observation is that not a single case was found with multiple interrogatives. Thus, forms like (15), from Radford (1997: 136), simply did not occur in all of the 57 million-word corpus, and therefore it seems a moot point to argue about the validity of the "neat account" offered by checking theory for "why only one wh-operator is preposed in multiple wh-questions in English" (Radford 1997: 136).

(15) Who do you think will say what?

The basic data, representing the patterns in the corpus, are reported in tables 1-3. Table 1 shows that the verb dink 'think' is used in the overwhelming majority of cases, and only the 
verbs sê 'say', reken 'reckon/guess', and meen 'mean/suppose' contribute more than $1 \%$ of the total number of instances of this construction. In the entire corpus, a mere 11 verbs are used as the verb of the CTP, or main clause, with seven of those at negligible frequencies.

Table 1. CTP-verbs in the wh-extraction construction

\begin{tabular}{|l|r|r|}
\hline Verb & $\mathbf{N}$ & $\mathbf{\%}$ \\
\hline dink 'think' & 708 & 80,4 \\
\hline sê 'say' & 113 & 12,8 \\
\hline reken 'reckon/guess' & 35 & 4,0 \\
\hline meen 'mean/suppose' & 10 & 1,1 \\
\hline voorstel 'suggest' & 5 & 0,6 \\
\hline vra 'ask' & 4 & 0,5 \\
\hline afvra 'ask' & 2 & 0,2 \\
\hline beskou 'view' & 1 & 0,1 \\
\hline glo 'believe' & 1 & 0,1 \\
\hline hê 'have' & 1 & 0,1 \\
\hline verwag 'expect' & 1 & 0,1 \\
\hline Total & 881 & 100,0 \\
\hline
\end{tabular}

The lexically-specific and non-general quality of the construction is also evident from a consideration of the other elements of the CTP, except for the wh-word itself, which shows some variability, ranging from wat 'wat' (with a raw frequency of 360), waarom 'why' (147), hoekom 'why' (121) and hoe 'how' (97) to low frequency interrogatives like waar 'where' (25), waaraan 'of what' (1) and waarin 'in what' (1). As shown in table 2, variation as far as subjects are concerned is even more limited than variation of the verbs, except for the difference in formality of the second-person singular pronouns.

Table 2. CTP-subjects in wh-extraction

\begin{tabular}{|l|r|r|}
\hline CTP subject & $\mathbf{N}$ & $\mathbf{\%}$ \\
\hline jy 'you' & 605 & 68,7 \\
\hline$u$ 'you' & 200 & 22,7 \\
\hline Noun phrase & 36 & 4,1 \\
\hline julle 'you' (plural) & 17 & 1,9 \\
\hline hy 'he' & 11 & 1,2 \\
\hline sy 'she' & 7 & 0,8 \\
\hline hulle 'they' & 4 & 0,5 \\
\hline ek 'I' & 1 & 0,1 \\
\hline Total & 881 & 100,0 \\
\hline
\end{tabular}

These two findings confirm the trend reported for Dutch by Verhagen (2005: 124), but actually show an even stronger concentration of forms on the prototype pattern, i.e. WH DINK $\mathrm{JY} / \mathrm{U}+$ CLAUSE. Afrikaans differs from Dutch in that the complementiser $d a t$ 'that' is absent from all but three examples, and is therefore clearly not part of the construction schema. This is not surprising, in view of the finding of Kruger and Van Rooy (2015) that the interpersonal use of the complement construction is marked by the absence of the complementiser, as shown in example (12). 
Of the 881 instances of the construction, only two are in the past tense. Modals also occur in a limited sense, except with the verb $s \hat{e}$ 'say', which strongly prefers to occur with a modal rather than in the present tense. Table 3 shows the combined patterns of modal or tense use with various other combinations in the data. The prototype status of WH DINK JY/U is confirmed in Table 3, where all patterns that occurred at least 10 times are listed.

Table 3. Combinations of elements in CTPs with modals

\begin{tabular}{|l|l|r|r|}
\hline CTP verb & Patterns & Frequency & $\mathbf{( \% )}$ \\
\hline dink 'think' (N=708) & WH dink jy/u + clause & 645 & $(92)$ \\
& WH dink NP + clause & 30 & $(4)$ \\
& WH dink julle + clause & 12 & $(2)$ \\
& WH dink hy + clause & 10 & $(1)$ \\
\hline sê 'say' (N=113) & WH sou jy/u dink + clause & 97 & $(86)$ \\
& WH sal jy/u dink + clause & 13 & $(12)$ \\
\hline reken 'reckon/guess' (N=35) & WH reken jy/u + clause & 24 & $(68)$ \\
& WH sou jy/u reken + clause & 10 & $(29)$ \\
\hline
\end{tabular}

Only for the verb dink 'think' is there some variation in terms of the subject, but still representing below $10 \%$ of all cases, and there is no use of modals with the verb dink, as exemplified by (16).

(16) Waarin dink jy lê die oplossing om die leemte wat die adolessent mag ervaar uit te skakel of te beperk? (TK)

'In what do you think lies the solution to eliminate or restrict the gap experienced by the adolescent?'

However, when the CTP verb is $s \hat{e}$ 'say' the picture changes. In general, sê occurs almost five times more frequently in the corpus than dink (approximately 2800 against 600 per million words), but in this construction, the less prototypical use of $s \hat{e}$ is cued by its combination with a modal auxiliary, either sou 'would' or sal 'shall', as exemplified by (17).

(17) Wat sou jy sê is jou sterkste eienskappe as atleet? (TK)

'What would you say are your strongest attributes as athlete?'

The verb reken 'reckon/guess' accounts for an even smaller proportion of cases, only 35, thus less than 1 per million words. Two thirds occur without a modal, but about a third of instances make use of the modal sou 'would', like sê 'say'. These two patterns are illustrated in (18) and (19).

(18) Wat reken jy sal die resultaat van 'n belastingverhoging op voedsel wees? (TK) 'What do you reckon will be the result of a tax increase on food?'

(19) Waarom, sou jy reken, is jou rol as Bewegingskundige baie belangrik in die identifisering asook die vroeë uitkenning van groot motoriese agterstande? (TK) 'Why, would you reckon, is your role of biokineticist very important in the identification as well as early recognition of large motor deficits?'

The Afrikaans data confirm and strengthen the findings from the much smaller Dutch data set reported by Verhagen (2005) and the findings of Gast et al. (2011) for English. The prototype 
for the construction is clearly WH DINK JY/U + CLAUSE, with minimal extension to either another verb, from a small set, or another subject, but only with the verb dink 'think'. The function of the construction is also similar to the function attributed to the construction in Dutch, viz. an interpersonal meaning in which the addressee is invited by the speaker to coordinate perspectives. Thus, the speaker checks whether s/he and the addressee share a particular conceptualisation in the prototypical case. In this respect, the CTP dink jy and the other variants do not function as some superordinate clause, but represent a different kind of meaning, orthogonal to the representational function of the complement clause. The phrase dink jy is in a sense omissible and mobile, and can therefore even be moved to the end of the clause, or omitted altogether without loss of meaning, as exemplified by (20).

(20) Wat dink jy gaan my skoonma en my tuinman sê as ek hulle elke oggend moet saampiekel?

'What do you think will my mother-in-law and my gardener say if I take them along every morning?'

(20') Wat gaan my skoonma en my tuinman sê as ek hulle elke oggend moet saampiekel?

(20") Wat gaan my skoonma en my tuinman sê as ek hulle elke oggend moet saampiekel, dink jy?

A construction-based approach demonstrates that wh-extraction is not a general construction that necessitates movement and constraints on the movement, formulated at a most general level. It is a simple construction, with a salient and specific schema, which we propose is represented as $\mathrm{WH}$ [DINK JY/U] + CLAUSE, and allows for minimal extension to the variants WH [SOU JY/U SÊ] + CLAUSE or WH [REKEN JY/U] + ClAUSE. Other forms can be formed by analogy to the basic construction schema, but in general they are quite rare and usually one-off creations, as the data clearly show. Therefore, the construction has limited schematicity and is nowhere as general as the range of examples invented by generative analyses purports to suggest.

Support for the functional interpretation of the construction as an interpersonal extension is provided by Verhagen (2005) and Kruger and Van Rooy (2015). As far as Afrikaans is concerned, Kruger and Van Rooy (2015) find that the omission of dat 'that' and the main clause word order of the complement clause elevates the propositional content of the complement clause to discourse-central status, overriding the presumed main-clause status of the interpersonal predicate dink jy. The $\mathrm{WH}$ [DINK JY/U] + CLAUSE construction therefore inherits its interpersonal, as opposed to propositional, meaning in part from the more general "complement construction", of which it can be regarded as a specific instantiation (Verhagen 2005: 126-127). As Verhagen (2005: 149-155) argues, the propositional dimension of discourse is conveyed by the clause that is conventionally designated the "complement clause", while the CTP presents a parallel dimension of interpersonal coordination between the participants in a conversational exchange.

This interpretation is lost if a strict separation is maintained between syntactic form and the function of the construction, and necessitates an extensive statement of the lexically restricted nature of the "movement" to account for the limited range of forms actually attested in a large corpus (unless, of course, this set of facts is ignored as "mere performance" or "mere pragmatics"). The generative analysis of wh-extraction, we argue, is misleading in attributing a generality to the process that is not supported by the data. Given the template of direct 
interrogatives, which is considerably more productive than the wh-extraction examples (99 vs 1 out of every 100), the extension to the interpersonal domain should simply be taken as a parenthetical confirmation check (dink jy 'do you think'/sou jy sê 'would you say'), and is therefore not a complex structure at all. No deep, general principles are required to act as constraint on movement. Rather the construction appears to be a simple, and minimal, extension of the direct wh-interrogative (illustrated by (20') above) through the insertion of a lexically-specific chunk dink $j y / u$. The construction grammar approach explains the development of this construction as a blended form that comes into being by combining the direct interrogative and the interpersonal variant of the complement clause.

\section{Conclusion}

Emergentism, as represented by construction grammar, offers a viable alternative to the nativist approach, as represented by generativism. Emergentism rejects a number of idealisations such as the competence/performance distinction and the separation of syntax and meaning in the derivation of linguistic forms. By adopting a usage-based approach to grammar and taking the construction as central unit of analysis, a different picture of linguistic form appears in which linguistic complexity is not such a dominant reference point that an innate mechanism needs to be postulated to guide the process of language acquisition.

The emergentist alternative to complexity is that a construction emerges, and once entrenched as a new unit, much of the original compositional complexity disappears. Thus, seemingly complex forms are only complex if they are analysed in terms of a range of constituents that have to be combined in a derivation every time a construction is used. If the construction itself is acknowledged as a central unit for the representation of grammatical knowledge, the entrenched unit takes on a life of its own, unaware of its genesis in a combination of different structures. What is stored in the mind of the user, as Bybee (2010), Croft (2001), Goldberg (1995), Langacker $(1987,1991)$ and Tomasello (2009) argue, is a network of related linguistic constructions that emerge from interaction between people and exposure to data. The development of these constructions proceeds on the basis of general cognitive mechanisms, rather than mechanisms that are modality-specific to language, and is constrained by the processing capacity of the brain (Hawkins 2004, 2014; O'Grady 2008, 2012, 2015).

Using this approach, we offered an alternative analysis of the wh-extraction construction, which demonstrates how it can be regarded as a lexically specific construction schema that fits into a broader, more schematic network of complementation constructions. The interpersonal and propositional dimensions of language are integrated, but not so much as hierarchical units that move around. Alternatively, in the spirit of Sinclair and Mauranen (2006), there is a pattern of linear alternation between "complement clauses" and CTPs, where the former carry the propositional information and move the information offering in the discourse along, while the latter manage the interpersonal interaction between speakers. The various parts are structured schemas that blend into complete utterances. Complete utterances come into being through the application of processes like chunking, categorisation, and analogy (Bybee 2010), rather than language-specific movement constraints. 


\section{Acknowledgement}

The authors acknowledge the financial support of the National Research Foundation. However, the views expressed in this article are those of the authors and should not be attributed to the NRF.

\section{References}

Berwick, R.C., A.D. Friederici, N. Chomsky and J.J. Bolhuis. 2013. Evolution, brain, and the nature of language. Trends in Cognitive Sciences 17(2): 89-98.

Boye, K. and P. Harder. 2007. Complement-taking predicates: Usage and linguistic structure. Studies in Language 31(3): 569-606.

Brinton, L.J. 2008. The comment clause in English: Syntactic origins and pragmatic development. Cambridge: Cambridge University Press.

Bybee, J. 2006. From usage to grammar: The mind's response to repetition. Language 82: 711-733.

Bybee, J. 2010. Language, usage and cognition. Cambridge: Cambridge University Press.

Chomsky, N. 1957. Syntactic structures. The Hague: Mouton.

Chomsky, N. 1959. Review of Verbal Behavior by B.F. Skinner. Language 35(1): 26-58.

Chomsky, N. 1965. Aspects of the theory of syntax. Cambridge, Mass.: MIT Press.

Chomsky, N. 1972. Language and mind. New York: Harcourt, Brace, Jovanovich.

Chomsky, N. 1977. On wh-movement. In P.W. Culicover, T. Wasow and A. Akmajian (Eds.). Formal syntax. New York: Academic Press. pp. 71-132.

Chomsky, N. 1981. Lectures on government and binding. Dordrecht: Foris.

Chomsky, N. 1986. Knowledge of language: Its nature, origin, and use. New York: Praeger.

Chomsky, N. 1995. The minimalist program. Cambridge, Mass.: MIT Press.

Chomsky, N. 2000. New horizons in the study of language and mind. Cambridge: Cambridge University Press.

Chomsky, N. 2007. Of minds and language. Biolinguistics 1: 9-27.

Christiansen, M.H. and N. Chater. 2008. Language as shaped by the brain. Behavioral and Brain Sciences 31: 489-558. 
Cook, V.J. and M. Newson. 1996. Chomsky's Universal Grammar: An introduction (2 ${ }^{\text {nd }}$ Ed.). Oxford: Blackwell.

Crain, S. 1991. Language acquisition in the absence of experience. Behavioral and Brain Sciences 14(4): 597-650.

Crain, S. and Pietroski, P. 2002. Why language acquisition is a snap. The Linguistic Review 19: $163-183$.

Croft, W. 1995. Autonomy and functionalism in linguistics. Language 71(3): 490-532.

Croft, W. 2000. Explaining language change: An evolutionary approach. London: Longman.

Croft, W. 2001. Radical construction grammar. Oxford: Oxford University Press.

Croft, W. 2007. Construction grammar. In D. Geeraerts and H. Cuykens (Eds.). The Oxford handbook of cognitive linguistics. Oxford: Oxford University Press. pp. 463-508.

Dawkins, R. 2009. The greatest show on earth: The evidence for evolution. London: Random House.

Dennett, D. 2013. Intuition pumps and other tools for thinking. New York: W.W. Norton.

Diessel, H. and M. Tomasello. 2001. The acquisition of finite complement clauses in English: A corpus-based analysis. Cognitive Linguistics 12(2): 97-141.

Du Plessis, H. 1977. Wh-movement in Afrikaans. Linguistic Inquiry 8(4): 723-726.

Fillmore, C.J. and P. Kay. 1999. Grammatical constructions and linguistic generalizations: The What's X doing Y? construction. Language 75(1): 1-33.

Gast, V., B. Bickel and L. Bierkandt. 2011. Towards a corpus-based typology of clauselinkage: A study of cross-clausal extraction. Unpublished guest lecture, Hamburg, 5 September 2011. Available online: http://linktype.iaa.uni-jena.de/files/05_09_2011_Towards_CorpusBased_Typology.pdf (Accessed 10 June 2015).

Givón, T. 2005. Context as other minds: The pragmatics of sociality, cognition and communication. Amsterdam: John Benjamins.

Givón, T. 2009. The genesis of syntactic complexity: Diachrony, ontogeny, neuro-cognition, evolution. Amsterdam: John Benjamins.

Goldberg, A.E. 1995. Constructions: A construction grammar approach to argument structure. Chicago: University of Chicago Press.

Hauser, M.D., N. Chomsky and W.T. Fitch. 2002. The faculty of language: What it is, who has it, and how did it evolve? Science 298: 1569-1579. 
Hawkins, J.A. 2004. Efficiency and complexity in grammars. Oxford: Oxford University Press.

Hawkins, J.A. 2014. Cross-linguistic variation and efficiency. Oxford: Oxford University Press.

Heine, B. and T. Kuteva. 2007. The genesis of grammar: A reconstruction. Oxford: Oxford University Press.

Hornstein, N., J. Nunes and K.K. Grohmann. 2005. Understanding minimalism. Cambridge: Cambridge University Press.

Hopper, P.J. 1998. Emergent grammar. In M. Tomasello (Ed.). The new psychology of language: Cognitive and functional approaches to language structure. Mahwah, NJ: Erlbaum. pp. 155-175.

Hopper, P.J. and E.C. Traugott. 1993. Grammaticalization. Cambridge: Cambridge University Press.

Kaltenböck, G. 2013. The development of comment clauses. In B. Aarts, J. Close, G. Leech and S. Wallis (Eds.). The verb phrase in English: Investigating recent language change with corpora. Cambridge: Cambridge University Press. pp. 155-175.

Kruger, H. and B. van Rooy. (2015). Verb complement clauses in Afrikaans: A case for constructional differentiation. Unpublished manuscript, available on order from authors.

Langacker, R.W. 1987. Foundations of Cognitive Grammar. Volume I: Theoretical prerequisites. Stanford: Stanford University Press.

Langacker, R.W. 1991. Foundations of Cognitive Grammar. Volume II: Descriptive application. Stanford: Stanford University Press.

Lieven, E., H. Behrens, J. Spears and M. Tomasello. 2003. Early syntactic creativity: A usage-based approach. Journal of Child Language 30: 333-370.

MacWhinney, B. 2010. Computational models of child language learning: An introduction. Journal of Child Language 37: 477-485.

O’Grady, W. 2008. The emergentist program. Lingua 118: 447-464.

O'Grady, W. 2012. Three factors in the design and acquisition of language. Wiley Interdisciplinary Reviews: Cognitive Science 3, 493-499.

O'Grady, W. 2015. Anaphora and the case for emergentism. In B. MacWhinney \& W. O'Grady (Eds.). The handbook of language emergence. Boston: Wiley-Blackwell. pp. 100-122.

O'Grady, W., M. Lee and H. Kwak. 2009. Emergentism and second language acquisition. In W. Ritchie \& T. Bhatia (Eds.). The new handbook of second language acquisition. Bingley: Emerald Press. pp. 69-88. 
Pinker, S. 1994. The language instinct. London: Penguin.

Pinker, S. 1999. Words and rules. London: Penguin.

Pinker, S. and P. Bloom. 1990. Natural language and natural selection. Behavioral and Brain Sciences 13(4): 707-784.

Pinker, S. and R. Jackendoff. 2005. The faculty of language: What's special about it? Cognition 95: 201-236.

Ponelis, F.A. 1979. Afrikaanse sintaksis. Pretoria: Van Schaik.

Pullum, G.K. and B.C. Scholz. 2002. Empirical assessment of stimulus poverty arguments. The Linguistic Review 19: 9-50.

Radford, A. 1983. Transformational syntax: A student's guide to Chomsky's Extended Standard Theory. Cambridge: Cambridge University Press.

Radford, A. 1997. Syntax: A minimalist introduction. Cambridge: Cambridge University Press.

Sampson, G. 2002. Exploring the richness of the stimulus. The Linguistic Review 19: 73-104.

Sampson, G. 2005. The 'language instinct' debate (revised ed.). London: Continuum.

Scott, M. 2012. WordSmith Tools version 6. Liverpool: Lexical Analysis Software.

Sinclair, J.M. and A. Mauranen. 2006. Linear unit grammar: Integrating speech and writing. Amsterdam: Benjamins.

Stroik, T.S. 2009. Locality in minimalist syntax. Cambridge, Mass.: MIT Press.

Taalkommissie van die Suid-Afrikaanse Akademie vir Wetenskap en Kuns. 2011. Taalkommissiekorpus 1.1. Potchefstroom: CTexT, North-West University.

Taylor, J.R. 1995. Linguistic categorization: Prototypes in linguistic theory ( ${ }^{\text {nd }}$ Ed.). Oxford: Clarendon.

Traugott, E.C. 1995. Subjectification in grammaticalisation. In D. Stein and S. Wright (Eds.). Subjectivity and subjectivisation: Linguistic perspectives. Cambridge: Cambridge University Press. pp. 31-54.

Thompson, S.A. 2002. "Object complements" and conversation: Towards a realistic account. Studies in Language 26(1): 125-164.

Thompson, S.A. and A. Mulac. 1991. The discourse conditions for the use of the complementizer that in conversational English. Journal of Pragmatics 15(3): 237-251. 
Tomasello, M. 2003. Constructing a language: A usage-based theory of language acquisition. Cambridge, Mass.: Harvard University Press.

Tomasello, M. 2008. Origins of human communication. Cambridge, Mass.: MIT Press.

Tomasello, M. 2009. The usage-based theory of language acquisition. In E.L. Bavin (Ed.). The Cambridge handbook of child language. Cambridge: Cambridge University Press. pp. 69-88.

Tomasello, M. 2014. A natural history of human thinking. Cambridge, Mass.: Harvard University Press.

Verhagen, A. 2005. Constructions of intersubjectivity: Discourse, syntax, and cognition. Oxford: Oxford University Press. 